\title{
Modeling the Pattern of Structural Change in U.S. Meat Demand
}

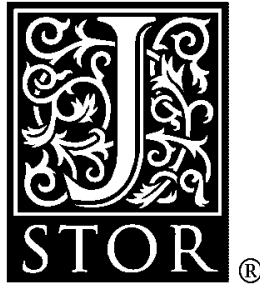

\author{
Giancarlo Moschini; Karl D. Meilke
}

American Journal of Agricultural Economics, Vol. 71, No. 2. (May, 1989), pp. 253-261.

Stable URL:

http://links.jstor.org/sici?sici=0002-9092\%28198905\%2971\%3A2\%3C253\%3AMTPOSC\%3E2.0.CO\%3B2-J

American Journal of Agricultural Economics is currently published by American Agricultural Economics Association.

Your use of the JSTOR archive indicates your acceptance of JSTOR's Terms and Conditions of Use, available at

http://www.jstor.org/about/terms.html. JSTOR's Terms and Conditions of Use provides, in part, that unless you have obtained prior permission, you may not download an entire issue of a journal or multiple copies of articles, and you may use content in the JSTOR archive only for your personal, non-commercial use.

Please contact the publisher regarding any further use of this work. Publisher contact information may be obtained at http://www.jstor.org/journals/aaea.html.

Each copy of any part of a JSTOR transmission must contain the same copyright notice that appears on the screen or printed page of such transmission.

The JSTOR Archive is a trusted digital repository providing for long-term preservation and access to leading academic journals and scholarly literature from around the world. The Archive is supported by libraries, scholarly societies, publishers, and foundations. It is an initiative of JSTOR, a not-for-profit organization with a mission to help the scholarly community take advantage of advances in technology. For more information regarding JSTOR, please contact support@ jstor.org. 


\title{
Modeling the Pattern of Structural Change in U.S. Meat Demand
}

\author{
Giancarlo Moschini and Karl D. Meilke
}

\begin{abstract}
The hypothesis of structural change in U.S. meat demand is tested in a four-meat almost ideal demand system with parameters following a gradual switching regression model. The results support the notion that structural change partly explains the observed U.S. meat consumption patterns. Structural change is biased against beef, neutral for pork, in favor of chicken and fish, and it does not affect estimated elasticities. The estimated path of structural change implies a rapid transition to a new regime in the mid-1970s, although a smooth path cannot be ruled out.
\end{abstract}

Key words: demand systems, meat demand, structural change, switching regressions.

Consumption patterns for meat products have changed considerably over the last few decades. This development is illustrated in figure 1 , which shows quarterly per capita meat consumption levels (pounds of retail weight for beef, pork, and chicken, and expenditure in 1987 dollars for fish and seafood). The most striking feature is the steady increase in chicken consumption, which has doubled in the last twenty years. Moreover, beef consumption declined sharply in the second half of the 1970 s. The significant gain in poultry productivity, and resulting lower real retail prices for poultry, can partly account for this phenomenon. Other explanations postulate a change in the structure of meat demand because of changes in income distribution, demographic variables, demand for convenience foods, and, above all, an evolution in consumers' preferences driven by a growing awareness of the health hazard of large intakes of cholesterol and other saturated fats.

Considerable research has analyzed the hypothesis of structural change in meat demand, including Braschler, Chalfant and Alston,

\footnotetext{
Giancarlo Moschini is an assistant professor of economics, Iowa State University. Karl Meilke is a professor of agricultural economics, University of Guelph.

Journal Paper No. J-13226 of the Iowa Agriculture and Home Economics Experiment Station, project 2875. Financial support for this research was provided by the Iowa Agriculture and Home Economics Experiment Station, the Social Sciences and Humanities Research Council of Canada, and the Ontario Ministry of Agriculture and Food.

The authors thank the Journal reviewers for constructive comments.
}

Chavas, Dahlgran, Eales and Unnevehr, Moschini and Meilke, Nyankori and Miller, Thurman, and Wohlgenant. The evidence from these studies is mixed, not surprisingly, given the variety of methods and data employed. In particular, determining whether consumers' preferences have changed has proved an elusive task. Because important features of the model generating the data are not known (e.g., the shape of utility functions) or are deliberately simplified for empirical tractability (e.g., by aggregating across commodities and/or across consumers), evidence of structural change may reflect model misspecification of some kind.

While these methodological problems possibly confine the analysis of structural change to the properties of an estimated model, the issue maintains its empirical relevance. Evidence of structural change is of considerable interest for the red meat industry because it implies a less favorable climate warranting adjustments in both production and marketing strategies. Econometric modeling for forecasting and policy analysis is also affected because changes in the data-generating process have direct bearings on model specification and estimation. Finally, as the issue hits the popular press, other implications seem to emerge. As Smith notes, "Cowboys, not chicken farmers, tamed the West." How will the United States adjust as it shifts from a nation of red meat-eating "cowboys" to a nation of white meateating "yuppies"?

The objective of this paper is to provide 


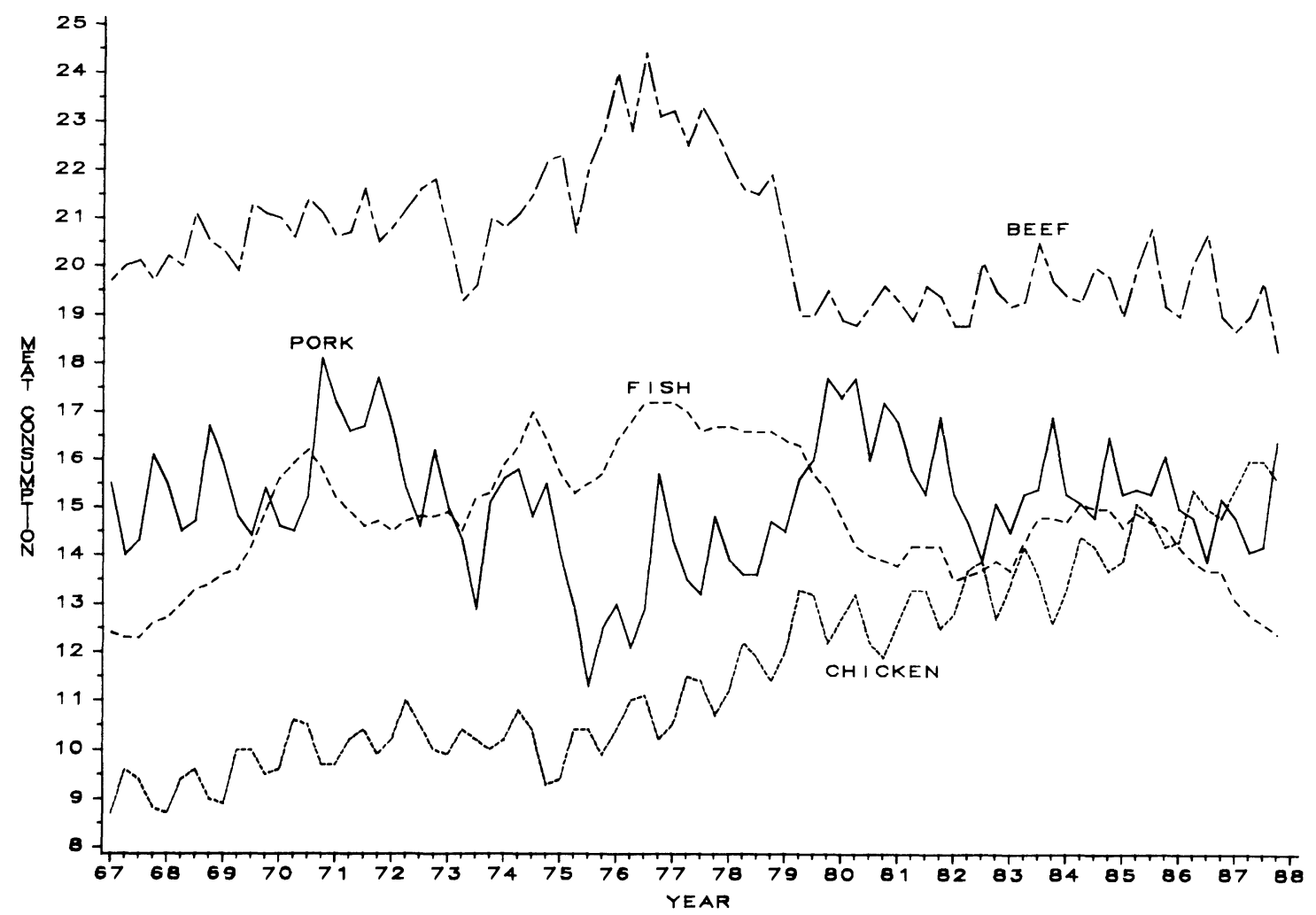

Figure 1. U.S. meat consumption (1967-I to 1987-IV)

further evidence of the existence and nature of structural change in meat demand. As in Christensen and Manser, attention is restricted to the demand for four meats (beef and veal, pork, chicken, and fish) by assuming weak separability between these products and all other goods. The analysis is carried out within a model satisfying acceptable definitions of flexibility and the restrictions of utility maximization. Quarterly data over the period 1967-I to 1987-IV are used. The focus of the analysis is to test for structural change in a model that can provide information on the time path of this change and to investigate the bias of structural change on consumption patterns and estimated elasticities.

\section{Model Specification}

The combined development of duality theory and flexible functional forms allows a number of system approaches to modeling consumer behavior (Deaton; Johnson, Hassan, and Green). In this paper we employ the linear version of the almost ideal demand system (AIDS) derived by Deaton and Muellbauer.
This model provides a first-order approximation to an arbitrary demand system and satisfies perfect aggregation conditions over consumers. In addition, the linearity of the AIDS model is an attractive feature for the econometric analysis of structural change.

The stochastic version of the system of share equations generated by the AIDS model can be written as

(1) $w_{i t}=\alpha_{i}+\Sigma_{j} \beta_{i j} p_{j t}+\beta_{i} x_{t}$

$$
+\Sigma_{k} \alpha_{i k} D_{k}+e_{i t}
$$

where $(i, j)=1, \ldots, 4$ index the goods, $t=1$, $\ldots, T$ indexes time, $p \equiv \ln (P)$ with $P$ denoting nominal prices, the $i$ th good share satisfies $w_{i}$ $\equiv\left(P_{i} Q_{i} / X\right)$ with $Q_{i}$ being the quantity demanded and $X$ total expenditures on the four goods, $x \equiv \ln \left(X / P^{*}\right)$ with $P^{*}$ being a price index which is approximated by the Stone geometric index $\left[\ln \left(\boldsymbol{P}^{*}\right)=\Sigma_{i} w_{i} p_{i}\right], k$ indexes three seasonal dummies denoted by $D$, and $e$ is an error term.

The theoretical properties of homogeneity in prices and income, and symmetry of the cross effects of demand functions, imply the following parametric restrictions on (1): 
(2.1) $\quad \Sigma_{j} \beta_{i j}=0$;

$$
\Sigma_{i} \alpha_{i}=1, \quad \Sigma_{i} \beta_{i j}=0, \quad \begin{array}{r}
\sum_{i} \beta_{i}=0, \\
\sum_{i} \alpha_{i k}=0 ;
\end{array}
$$

$$
\beta_{i j}=\beta_{i j} ;
$$

where (2.1) follows from the zero homogeneity of the share equations, (2.2) is the adding-up condition, and (2.3) is the Slutsky symmetry condition. ${ }^{1}$

Under the hypothesis of no structural change and assuming that the AIDS model provides a satisfactory approximation of the true demand system, the set of parameters $\{\alpha$, $\beta\}$ in equation (1) gives a full representation of the underlying utility maximization process. Structural change can be characterized by allowing this set of parameters to change over time. Given the cross-equation restrictions in (2), structural change likely will affect all equations simultaneously, so that a common time path for all parameters can be assumed. If this path is denoted $h_{t}$, equation (1) can be reparameterized as

(3) $w_{i t}=\alpha_{i}+\gamma_{i} h_{t}+\sum_{j}\left(\beta_{i j}+\delta_{i j} h_{t}\right) p_{j t}$ $+\left(\beta_{i}+\delta_{i} h_{t}\right) x_{t}+\Sigma_{k}\left(\alpha_{i k}+\gamma_{i k} h_{t}\right) D_{k}+e_{i t}$,

with the properties of homogeneity, adding up, and symmetry requiring the following additional parametric restrictions:

$$
\begin{aligned}
& \sum_{j} \delta_{i j}=0 \text {; } \\
& \Sigma_{i} \gamma_{i}=0, \quad \Sigma_{i} \delta_{i j}=0, \quad \Sigma_{i} \delta_{i}=0, \\
& \sum_{i} \gamma_{i k}=0 \text {; } \\
& \delta_{i j}=\delta_{j i} .
\end{aligned}
$$

Within this framework, a test for parameter constancy (that is, $\gamma=0$ and $\delta=0$ ) is a test for the hypothesis of no structural change. If the time path $h_{t}$ is approximated by a vector whose elements are 0 for the first half of the sample and 1 for the latter half, one obtains the Chow test for structural change. If the unknown path is approximated by the linear path $t / T$, one obtains the test studied by Farley and Hinich. To shed some light on the actual shape of this path, we follow Ohtani and Katayama and postulate that the structural change path can be approximated by

(5.1) $h_{t}=0$

$$
\text { for } t=1, \ldots, \tau_{1} \text {; }
$$

\footnotetext{
1 Because the adding-up conditions (2.2) will be satisfied by definition by the estimating model, the symmetry constraints (2.3) will always imply the remaining homogeneity restrictions (2.1).
}

$$
\begin{array}{ll}
h_{t}=\left(t-\tau_{1}\right) /\left(\tau_{2}-\tau_{1}\right) \\
& \text { for } t=\tau_{1}+1, \ldots, \tau_{2}-1 \\
h_{t}=1 \quad & \text { for } t=\tau_{2}, \ldots, T .
\end{array}
$$

Equations (5) imply that (3) becomes a gradual switching regression model, where $\tau_{1}$ represents the end point of the first regime and $\tau_{2}$ is the starting point of the second regime and where the transition path between the two regimes is linear. If $\tau_{2}=\tau_{1}+1$, the change in the coefficient vector is abrupt, whereas $\tau_{1}=0$ and $\tau_{2}=T$ produce the Farley-Hinich parameter path. ${ }^{2}$ To identify the structural change path, $\tau_{1}$ and $\tau_{2}$ are viewed as parameters and are estimated jointly with the other parameters of the system.

Finally, the set of equations (3) is expressed in first difference form for estimation purposes. The use of differencing allows a very parsimonious representation, in the spirit of Hendry and Mizon, of the dynamic behavior typical of frequent time-series data. Thus, the estimated model is

$$
\begin{aligned}
\Delta w_{i t}= & \gamma_{i} \Delta h_{t}+\sum_{j}\left[\beta_{i j} \Delta p_{j t}+\delta_{i j} \Delta\left(h_{t} p_{j t}\right)\right] \\
& +\beta_{i} \Delta x_{t}+\delta_{i} \Delta\left(h_{t} x_{t}\right) \\
& +\Sigma_{k}\left[\alpha_{i k} \Delta D_{k}+\gamma_{i k} \Delta\left(h_{t} D_{k}\right)\right]+u_{i t},
\end{aligned}
$$

with the parameter path $h_{t}$ given by equations (5).

Under the assumption that the error terms $u_{i t}$ in (6) are multinormally distributed but contemporaneously correlated with

$$
\begin{aligned}
E\left(u_{i t}\right) & =0, \\
E\left(u_{i t} u_{j t}\right) & =\omega_{i j}, \\
E\left(u_{i t} u_{j s}\right) & =0 \quad \text { for } t \neq s,
\end{aligned}
$$

maximum likelihood estimation can be performed for any given parameter path $h_{t}$. Given that $h_{t}$ in (6) has discontinuous derivatives with respect to $\tau_{1}$ and $\tau_{2}$, estimates of these two parameters are obtained by searching the likelihood function over the range of interest of $\left(\tau_{1}, \tau_{2}\right)$. Because of the adding-up condition $\sum_{i} \Delta w_{i}=0$, one of the equations in (6) is omitted at the estimation stage. Under the above stochastic assumptions, the maximum likelihood estimator is consistent, asymptotically

\footnotetext{
2 The approach of this paper has much in common with the gradual switching regressions model of Tsurumi, also applied to structural change in meat demand by Dahlgran. The main difference lies in the choice of the transition function for the path of structural change and in the fact that we allow structural change to affect all parameters simultaneously.
} 
normal, and asymptotically efficient and is independent of which equation is deleted (Barten).

\section{Data}

The data are quarterly disappearances and retail prices. For beef and pork, quantities are per capita disappearance in retail weight as published by the U.S. Department of Agriculture (USDA) in Livestock and Meat Situation (LMS) and in Livestock and Poultry Situation (LPS). The quantity of chicken is the total of young and mature chicken per capita disappearance as published by USDA in Poultry and Eggs Situation (PES) and in LPS. Personal consumption expenditure for fish and seafood on a quarterly basis was obtained from unpublished U.S. Department of Commerce (USDC) data; these data are expressed on per capita terms using estimates of U.S. population published in the Survey of Current Business (USDC). Retail prices for beef (choice) and pork as published in LMS and LPS, the retail price of frying chicken published in PES and LPS, and the CPI for fish and seafood from USDC are used. Prices and real income were divided by their sample mean before the logarithmic transformation, and the seasonal dummy variables are specified for the first three quarters.

\section{Results}

The first-difference AIDS model in (6) was estimated using the iterative seemingly unrelated regressions procedure available in SHAZAM 6.0, which converges to the maximum likelihood estimator. The model has three equations (the fish equation is omitted), and with the restrictions in (2) and (4) imposed, has forty-one free parameters. These parameters are estimated with 252 effective observations ( 3 equations and 84 quarters). To estimate the parameters of the structural change path, the system of equations was estimated for all the combinations of $\tau_{1}$ from $1967(1)$ to $1983(4)$ and $\tau_{2}$ from 1971(1) to 1987(4) (for $\tau_{1}<\tau_{2}$ ), This set of combinations ensures that all the parameters of the system are estimable and requires estimating the system of equations a total of 3,246 times.

The estimated coefficients for the three- equation system, conditional on the optimal $\left(\hat{\tau}_{1}, \hat{\tau}_{2}\right)$, are reported in table 1 , along with some single-equation statistics. ${ }^{3}$ The fit of the model is good for the pork and chicken equations and only satisfactory for the beef. (Note, however, that these $R^{2}$ coefficients measure the fit to a left-hand side defined as a first difference.) The Durbin-Watson statistics DW(1) (for autocorrelation of the first order) and DW(4) (for autocorrelation of the fourth order) reported in table 1 can be interpreted as a rough test of the validity of the dynamic specification and of the specification of structural change. These statistics show no evidence of autocorrelation in the residuals, suggesting that the specification of the model is acceptable. In particular, the use of first differences appears a useful, simplified dynamic specification device.

The values of the parameters defining the path of structural change that maximize the set of likelihood functions are $\hat{\tau}_{1}=1975-\mathrm{IV}$ and $\hat{\tau}_{2}$ $=$ 1976-III. These results suggest a rather abrupt change of regimes in the middle of the observation period, with the second regime starting at the peak of beef consumption. ${ }^{4}$ To investigate the significance of the structural change, table 2 reports likelihood ratio tests for the hypothesis of constancy of the parameter vector over time. The hypothesis of no structural change in the full set of parameters is rejected at the 0.05 significance level. Thus, a constant set of parameters cannot be postulated to rationalize consumer behavior within the assumed model, which suggests some degree of structural change over the period considered. To gain some insight into the nature of this change, the parameters are grouped into three distinct subsets. From table 2 it is apparent that the intercepts of the share equations and the seasonal components of these intercepts are subject to change, whereas the hypothesis of constant price and income parameters cannot be rejected.

Inference on the parameters defining the path of structural change is best done by considering restrictions on $\left(\tau_{1}, \tau_{2}\right)$. An interesting benchmark is given by the Farley-Hinich path $t / T$. This smooth structural change path is perhaps more consistent with changes in consumer preferences, which likely requires a

\footnotetext{
${ }^{3}$ The $R^{2}$ and D-W statistics are obtained from a regression of the observed shares on the estimated ones.

${ }^{4}$ Per capita beef consumption reached a maximum $24.4 \mathrm{lb}$./ quarter in 1976-III before experiencing a $20 \%$ decline in less than three years
} 
Table 1. Maximum Likelihood Parameter Estimates for the Time-Varying AIDS Model

\begin{tabular}{|c|c|c|c|c|c|c|c|c|c|c|c|}
\hline \multirow[b]{2}{*}{ Equation } & \multirow[b]{2}{*}{ Intercept } & \multicolumn{3}{|c|}{ Deflated Price } & \multirow[b]{2}{*}{ Expenditure } & \multicolumn{3}{|c|}{ Seasonal Dummies } & \multirow[b]{2}{*}{$R^{2}$} & \multirow[b]{2}{*}{ DW(1) } & \multirow[b]{2}{*}{ DW(4) } \\
\hline & & Beef & Pork & Chicken & & $\begin{array}{c}\text { First } \\
\text { Quarter }\end{array}$ & $\begin{array}{l}\text { Second } \\
\text { Quarter }\end{array}$ & $\begin{array}{c}\text { Third } \\
\text { Quarter }\end{array}$ & & & \\
\hline \multirow{2}{*}{ Beef } & & $\begin{array}{c}0.07189 \\
(0.02374)\end{array}$ & $\begin{array}{c}0.02982 \\
(0.01975)\end{array}$ & $\begin{array}{c}-0.05486 \\
(0.00850)\end{array}$ & $\begin{array}{c}0.11727 \\
(0.04424)\end{array}$ & $\begin{array}{c}0.00842 \\
(0.00172)\end{array}$ & $\begin{array}{c}0.01412 \\
(0.00259)\end{array}$ & $\begin{array}{c}0.01728 \\
(0.00190)\end{array}$ & \multirow[b]{2}{*}{0.76} & \multirow[b]{2}{*}{1.87} & \multirow[b]{2}{*}{1.89} \\
\hline & $\begin{array}{c}-0.02980 \\
(0.01348)\end{array}$ & $\begin{array}{c}0.00351 \\
(0.03134)\end{array}$ & $\begin{array}{c}-0.01312 \\
(0.02594)\end{array}$ & $\begin{array}{c}0.01096 \\
(0.01159)\end{array}$ & $\begin{array}{c}0.08197 \\
(0.06539)\end{array}$ & $\begin{array}{c}0.00234 \\
(0.00261)\end{array}$ & $\begin{array}{c}0.00001 \\
(0.00337)\end{array}$ & $\begin{array}{c}0.00053 \\
(0.00239)\end{array}$ & & & \\
\hline \multirow{2}{*}{ Pork } & & $\begin{array}{c}0.02982 \\
(0.01975)\end{array}$ & $\begin{array}{c}-0.00105 \\
(0.02053)\end{array}$ & $\begin{array}{c}-0.01180 \\
(0.00793)\end{array}$ & $\begin{array}{c}0.01121 \\
(0.04036)\end{array}$ & $\begin{array}{c}-0.00919 \\
(0.00158)\end{array}$ & $\begin{array}{c}-0.02409 \\
(0.00240)\end{array}$ & $\begin{array}{c}-0.02596 \\
(0.00173)\end{array}$ & \multirow[b]{2}{*}{0.90} & \multirow[b]{2}{*}{2.19} & \multirow[b]{2}{*}{1.64} \\
\hline & $\begin{array}{c}0.00883 \\
(0.01254)\end{array}$ & $\begin{array}{c}-0.01312 \\
(0.02594)\end{array}$ & $\begin{array}{c}0.03459 \\
(0.02695)\end{array}$ & $\begin{array}{c}-0.01881 \\
(0.01108)\end{array}$ & $\begin{array}{c}-0.05260 \\
(0.05956)\end{array}$ & $\begin{array}{c}-0.00465 \\
(0.00239)\end{array}$ & $\begin{array}{c}-0.00013 \\
(0.00311)\end{array}$ & $\begin{array}{c}0.00165 \\
(0.00217)\end{array}$ & & & \\
\hline \multirow{2}{*}{ Chicken } & & $\begin{array}{c}-0.05486 \\
(0.00850)\end{array}$ & $\begin{array}{r}-0.01180 \\
(0.00793)\end{array}$ & $\begin{array}{c}0.08082 \\
(0.00647)\end{array}$ & $\begin{array}{r}-0.07359 \\
(0.01929)\end{array}$ & $\begin{array}{c}0.00065 \\
(0.00066)\end{array}$ & $\begin{array}{c}0.00938 \\
(0.00100)\end{array}$ & $\begin{array}{c}0.00767 \\
(0.00073)\end{array}$ & \multirow[b]{2}{*}{0.94} & \multirow[b]{2}{*}{1.92} & \multirow[b]{2}{*}{1.90} \\
\hline & $\begin{array}{c}0.00869 \\
(0.00513)\end{array}$ & $\begin{array}{c}0.01096 \\
(0.01159)\end{array}$ & $\begin{array}{c}-0.01881 \\
(0.01108)\end{array}$ & $\begin{array}{c}0.00505 \\
(0.00984)\end{array}$ & $\begin{array}{c}-0.00980 \\
(0.02696)\end{array}$ & $\begin{array}{c}0.00260 \\
(0.00100)\end{array}$ & $\begin{array}{c}-0.00011 \\
(0.00129)\end{array}$ & $\begin{array}{c}-0.00082 \\
(0.00092)\end{array}$ & & & \\
\hline
\end{tabular}

Note: For each equation, the first row of coefficients refers to the fixed component of the parameters, and the second row is the time-varying component of the parameters; the

asymptotic standard errors (conditional on the estimated value of time path parameters) are reported in parentheses; maximized log-likelihood $=1,125.28$. 
Table 2. Likelihood Ratios for Structural Change Tests

\begin{tabular}{lcrr}
\hline & $\begin{array}{c}\text { Number } \\
\text { of } \\
\text { Restric- } \\
\text { tions }\end{array}$ & $\begin{array}{c}\text { Likeli- } \\
\text { hood } \\
\text { Ratio }\end{array}$ & $\chi_{0.05}^{2}$ \\
\hline Nypothesis & & & \\
$\quad \begin{array}{l}\text { change in: } \\
\text { all parameters }\end{array}$ & 18 & 45.06 & 28.87 \\
intercept parameters & 3 & 9.87 & 7.82 \\
$\quad$ price and expendi- & & & \\
$\quad$ ture parameters & 6 & 5.72 & 12.59 \\
$\quad$ seasonal parameters & 9 & 24.72 & 16.92 \\
Smooth structural change & 2 & 2.97 & 5.99 \\
\hline
\end{tabular}

gradual adjustment to new information. As the results in table 2 indicate, this hypothesis is not rejected at the $5 \%$ probability level. More generally, one can construct a confidence region for these two parameters over the explored parameter space. If $\left(\tau_{1}^{\circ}, \tau_{2}^{\circ}\right)$ denote any pair of structural change parameters, $\left(\tau_{1}^{\circ}\right.$, $\tau_{2}^{\circ}$ ) belongs to he confidence region if

$$
2\left[L\left(\hat{\tau}_{1}, \hat{\tau}_{2}\right)-L\left(\tau_{1}^{\circ}, \tau_{2}^{\circ}\right)\right] \leq \chi^{2},
$$

where $L($.) denotes the log-likelihood function concentrated with respect to all other parameters, and the chi-square critical value with two degrees of freedom is evaluated at both the $5 \%$ and the $10 \%$ significance level.

Of the 3,246 combinations of $\left(\tau_{1}, \tau_{2}\right)$ considered, 467 fall in the $95 \%$ confidence region, with 202 of them being also in the $90 \%$

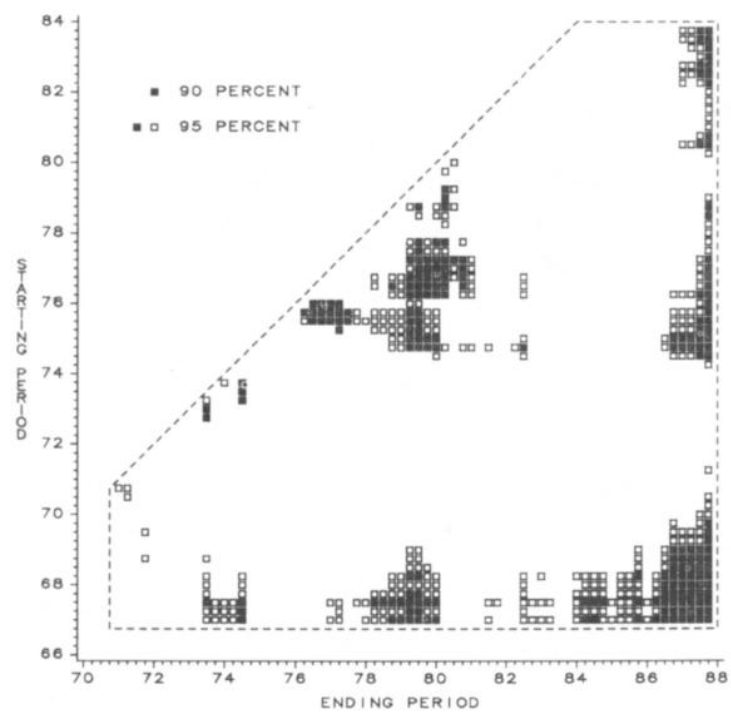

Figure 2. Confidence regions for structural change parameters confidence region. These confidence regions are illustrated in figure 2, where the broken line encloses the explored parameter space. While the estimated $\left(\hat{\tau}_{1}, \hat{\tau}_{2}\right)$ imply a sharp transition between two regimes, figure 2 suggests that a variety of structural change paths cannot be rejected. In addition to a break point in the middle of the sample, figure 2 suggests other likely paths, in particular one starting at the beginning and extending to the end of the period considered.

\section{Bias of Structural Change}

Previous studies have generally illustrated structural change in meat demand in terms of its effects on estimated elasticities. While this conveys information on whether demand reacts differently to variations in prices and expenditure levels due to structural change, it says nothing of the effects of structural change on quantity demanded with prices and expenditure level held constant. To illustrate this effect on consumption patterns, one can attribute bias to structural change if it significantly changes expenditure shares. If $w_{i}^{b}$ denotes the $i$ th good share before structural change, and $w_{i}^{a}$ is the same share after structural change, then a measure of bias is $B_{i} \equiv w_{i}^{a}-w_{i}^{b}$. Structural change will be biased against the $i$ th good if it resulted in a lower demand for this good, which would be implied by $B_{i}<0$. Conversely, $B_{i}>0$ implies that structural change is biased in favor of the $i$ th good. Evaluating the shares at the sample mean of the exogenous variables (such that $p_{j}=0, x=0$, and $D_{k}$ $=0.25)$, this measure reduces to

$$
B_{i}=\gamma_{i}+0.25\left(\Sigma_{k} \gamma_{i k}\right) \text {. }
$$

Table 3 reports the estimated biases and the

Table 3. Bias of Structural Change

\begin{tabular}{lcc}
\hline Share & Bias & $\begin{array}{c}\text { Mean } \\
\text { Share }\end{array}$ \\
\hline Beef & -0.0291 & 0.5050 \\
& $(0.0130)$ & \\
Pork & 0.0080 & 0.2803 \\
& $(0.0120)$ & \\
Chicken & 0.0091 & 0.1063 \\
Fish & $(0.0049)$ & \\
& 0.0119 & 0.1084 \\
Wald Test & $(0.0052)$ & \\
\hline
\end{tabular}

Note: standard errors are reported in parentheses. 
associated standard errors. Structural change is significantly biased against beef, in favor of chicken and fish, and it is neutral for pork. These biases are best understood when compared with the share values. For instance, the estimated bias for beef implies that a decline of approximately $6 \%$ in the beef share can be accounted for by the estimated changing structure at constant prices and expenditures. The hypothesis that the measures of bias reported in table 3 are simultaneously different from zero can be tested by the Wald test (Engle). This test, distributed as chi-square with three degrees of freedom because of the adding-up property, shows that the hypothesis of no bias of structural change can be rejected at the 0.05 significance level.

Another problem of interest is whether structural change has significantly affected demand elasticities. Marshallian elasticities that reflect the effects of structural change, and conditional on meat expenditures can be computed as

(9.1) $\epsilon_{i i}=\left(\beta_{i i}+\delta_{i i}\right) / w_{i}^{a}-\left(\beta_{i}+\delta_{i}\right)-1$,

(9.2) $\epsilon_{i j}=\left(\beta_{i j}+\delta_{i j}\right) / w_{i}^{a}-\left(\beta_{i}+\delta_{i}\right)\left(w_{j}^{a} / w_{i}^{a}\right)$,

(9.3) $\epsilon_{i x}=\left(\beta_{i}+\delta_{i}\right) / w_{i}^{a}+1$.

Elasticities that reflect demand response before structural change are obtained from (9) by setting the $\delta$ parameters to zero and substitut- ing $w_{i}^{b}$ for $w_{i}^{a}$. To compare elasticities evaluated at the same level of the exogenous variables, the mean of the estimated shares over the whole period is used to represent $w_{i}^{a}$, and $w_{i}^{b}$ is obtained by subtracting from $w_{i}^{a}$ the average bias measure reported in table 3 . The elasticities obtained are reported in table 4 , along with standard errors computed as in Chalfant by treating expenditure shares as constants.

The demands for beef and pork are much more elastic than chicken and fish. Notably, beef is the only superior good in both regimes. The cross-price elasticities show more complementarity relationships than expected, with ten of the twelve cross-price elasticities having a negative sign in both regimes. However, these are gross elasticities including an income effect, and many of them are not different than zero in statistical terms.

To test the hypothesis that elasticity values were unaffected by structural change, the standard errors of elasticity differences between the two regimes were computed. None of these individual elasticities are statistically different between the two regimes, and the Wald test reported in table 4 (and distributed as $\chi^{2}$ with 9 degrees of freedom) shows that, as a set, they are not significantly different at the $5 \%$ level.

Table 4. Estimated Marshallian Elasticities at the Sample Mean

\begin{tabular}{|c|c|c|c|c|c|}
\hline \multirow[b]{2}{*}{ Elasticity of } & \multicolumn{4}{|c|}{ Price of } & \multirow[b]{2}{*}{ Expenditure } \\
\hline & Beef & Pork & Chicken & Fish & \\
\hline & \multicolumn{4}{|c|}{ Before Structural Change } & \\
\hline Beef & $\begin{array}{c}-0.983 \\
(0.068)\end{array}$ & $\begin{array}{c}-0.004 \\
(0.038)\end{array}$ & $\begin{array}{c}-0.124 \\
(0.016)\end{array}$ & $\begin{array}{c}-0.109 \\
(0.023)\end{array}$ & $\begin{array}{c}1.220 \\
(0.083)\end{array}$ \\
\hline Pork & $\begin{array}{c}0.087 \\
(0.119)\end{array}$ & $\begin{array}{r}-1.015 \\
(0.075)\end{array}$ & $\begin{array}{r}-0.047 \\
(0.029)\end{array}$ & $\begin{array}{r}-0.066 \\
(0.040)\end{array}$ & $\begin{array}{c}1.041 \\
(0.148)\end{array}$ \\
\hline Chicken & $\begin{array}{c}-0.161 \\
(0.147)\end{array}$ & $\begin{array}{c}0.086 \\
(0.092)\end{array}$ & $\begin{array}{c}-0.090 \\
(0.061)\end{array}$ & $\begin{array}{c}-0.073 \\
(0.073)\end{array}$ & $\begin{array}{c}0.238 \\
(0.200)\end{array}$ \\
\hline \multirow[t]{2}{*}{ Fish } & $\begin{array}{c}-0.182 \\
(0.143)\end{array}$ & $\begin{array}{c}-0.021 \\
(0.094)\end{array}$ & $\begin{array}{r}-0.092 \\
(0.054)\end{array}$ & $\begin{array}{c}-0.138 \\
(0.140)\end{array}$ & $\begin{array}{c}0.432 \\
(0.247)\end{array}$ \\
\hline & \multicolumn{4}{|c|}{ After Structural Change } & \\
\hline Beef & $\begin{array}{c}-1.050 \\
(0.064)\end{array}$ & $\begin{array}{c}-0.078 \\
(0.041)\end{array}$ & $\begin{array}{c}-0.129 \\
(0.018)\end{array}$ & $\begin{array}{c}-0.138 \\
(0.021)\end{array}$ & $\begin{array}{c}1.394 \\
(0.093)\end{array}$ \\
\hline Pork & $\begin{array}{c}0.134 \\
(0.101)\end{array}$ & $\begin{array}{c}-0.839 \\
(0.072)\end{array}$ & $\begin{array}{c}-0.093 \\
(0.032)\end{array}$ & $\begin{array}{c}-0.054 \\
(0.033)\end{array}$ & $\begin{array}{c}0.853 \\
(0.153)\end{array}$ \\
\hline Chicken & $\begin{array}{c}-0.017 \\
(0.114)\end{array}$ & $\begin{array}{c}-0.068 \\
(0.084)\end{array}$ & $\begin{array}{c}-0.104 \\
(0.072)\end{array}$ & $\begin{array}{c}-0.022 \\
(0.059)\end{array}$ & $\begin{array}{c}0.211 \\
(0.172)\end{array}$ \\
\hline Fish & $\begin{array}{c}-0.098 \\
(0.110)\end{array}$ & $\begin{array}{c}0.012 \\
(0.077)\end{array}$ & $\begin{array}{c}-0.032 \\
(0.055)\end{array}$ & $\begin{array}{c}-0.196 \\
(0.084)\end{array}$ & $\begin{array}{c}0.314 \\
(0.165)\end{array}$ \\
\hline
\end{tabular}

Note: Asymtotic standard errors are reported in parentheses; Wald test $=11.88$ (for equality of elasticities in the two regimes). 
The elasticity effects of structural change are further illustrated in table 5, which reports the Allen elasticities of substitution, again evaluated before and after the structural change. The elasticities of substitution that reflect the effects of structural change are defined as

$$
\begin{array}{ll}
(10.1) & \sigma_{i i}=\left(\beta_{i i}+\delta_{i i}\right) /\left(w_{i}^{a}\right)^{2}-1 / w_{i}^{a}+1, \\
(10.2) & \sigma_{i j}=\left(\beta_{i j}+\delta_{i j}\right) /\left(w_{i}^{a} w_{j}^{a}\right)+1,
\end{array}
$$

and, as before, elasticities before structural change can be obtained by setting the $\delta$ parameters in (10) to zero, and substituting $w_{i}^{b}$ for $w_{i}^{a}$. Table 5 shows no statistically significant complementarity relations. The strongest substitutability relationships are between beef and pork in both regimes and between pork and chicken before structural change. After structural change, a substitutability relationship is more evident between beef and chicken.

None of these elasticities, however, are statistically different between the two regimes. The Wald test in table 5 (distributed as $\chi^{2}$ with 6 degrees of freedom) shows that these elasticities, as a group, are not statistically different between the two regimes at the 5\% significance level. This suggests that emphasizing the effect of structural change on estimated elasticities may be unjustified in

Table 5. Estimated Elasticities of Substitution

\begin{tabular}{|c|c|c|c|c|}
\hline & Beef & Pork & Chicken & Fish \\
\hline & \multicolumn{3}{|c|}{ Before Structural Change } & \\
\hline Beef & $\begin{array}{c}-0.620 \\
(0.083)\end{array}$ & $\begin{array}{l}1.205 \\
(0.136)\end{array}$ & $\begin{array}{c}-0.063 \\
(0.165)\end{array}$ & $\begin{array}{c}0.092 \\
(0.197)\end{array}$ \\
\hline Pork & & $\begin{array}{c}-2.682 \\
(0.276)\end{array}$ & $\begin{array}{c}0.552 \\
(0.301)\end{array}$ & $\begin{array}{c}0.356 \\
(0.338)\end{array}$ \\
\hline Chicken & & & $\begin{array}{r}-0.690 \\
(0.694)\end{array}$ & $\begin{array}{r}-0.518 \\
(0.635)\end{array}$ \\
\hline \multirow[t]{2}{*}{ Fish } & & & & $\begin{array}{r}-0.995 \\
(1.257)\end{array}$ \\
\hline & \multicolumn{3}{|c|}{ After Structural Change } & \\
\hline Beef & $\begin{array}{c}-0.684 \\
(0.080)\end{array}$ & $\begin{array}{l}1.118 \\
(0.119)\end{array}$ & $\begin{array}{c}0.178 \\
(0.148)\end{array}$ & $\begin{array}{c}0.121 \\
(0.158)\end{array}$ \\
\hline Pork & & $\begin{array}{c}-2.137 \\
(0.221)\end{array}$ & $\begin{array}{c}-0.032 \\
(0.261)\end{array}$ & $\begin{array}{c}0.356 \\
(0.244)\end{array}$ \\
\hline Chicken & & & $\begin{array}{r}-0.774 \\
(0.661)\end{array}$ & $\begin{array}{c}0.010 \\
(0.494)\end{array}$ \\
\hline Fish & & & & $\begin{array}{r}-1.492 \\
(0.723)\end{array}$ \\
\hline
\end{tabular}
at the Sample Mean

Note: Asymtotic standard errors are reported in parentheses; Wald test $=6.05$ (for equality of elasticities in the two regimes). some cases and that more can be gained by focusing on the bias on consumption patterns (estimated shares).

\section{Conclusions}

The evidence presented in this paper supports the idea that the observed meat consumption patterns of the last two decades cannot be fully explained by the dynamics of prices and income. The hypothesis of constancy of the parameters of a reasonably specified AIDS model for four meats was rejected against a more general time-varying parameter model. This finding was further qualified by the estimated distorting effects of structural change. The time-varying component of the model is biased against beef and in favor of chicken and fish. While this analysis does not identify the roots of this bias, this movement toward an increased importance of white meats further supports the idea that dietary concerns are partly responsible for the perceived changes in meat consumption patterns. The implications of this are particularly relevant for the beef industry, calling possibly for a quality adjustment in production and increased efforts in promotion and marketing.

Evidence of a changing structure of meat demand also has implications for econometric policy analysis and forecasting. For econometric models to deal adequately with the changing structure, it is useful to know the time path of structural change. The point estimates of the structural change parameters indicate a fairly rapid transition to a new demand regime in the mid-1970s, suggesting the use of post-1976 data as a viable modeling strategy. Some caution is warranted, however, because a variety of time paths for structural change cannot be ruled out by the model.

\section{[Received May 1988; final revision received September 1988.]}

\footnotetext{
References

Barten, A. P. "Maximum Likelihood Estimation of a Complete System of Demand Equations.' Eur. Econ. Rev. 1(1969):7-73.

Braschler, C. "The Changing Demand Structure for Pork and Beef in the 1970s: Implications for the 1980s." $S$. J. Agr. Econ. 15(1983):105-10.
} 
Chalfant, J. A. "A Globally Flexible, Almost Ideal Demand System." J. Bus. and Econ. Statist. 5(1987):233-42.

Chalfant, J. A., and J. M. Alston. "Accounting for Changes in Tastes." J. Polit. Econ. 96(1988):391410.

Chavas, J.-P. "Structural Change in the Demand for Meat." Amer. J. Agr. Econ. 65(1983):148-53.

Chow, G. C. "Tests of Equality between Subsets of Coefficients in Two Linear Regressions." Econometrica 28(1960):591-605.

Christensen, L. R., and M. E. Manser. "Estimating U.S. Consumer Preferences for Meat with a Flexible Utility Function."' J. Econometrics 5(1977):37-53.

Dahlgran, R. A. "Complete Flexibility Systems and the Stationarity of U.S. Meat Demand." West. J. Agr. Econ. 12(1987): 152-63.

Deaton, A. "Demand Analysis." Handbook of Econometrics, vol. 3, ed. Z. Griliches and M. D. Intriligator. New York: Elsevier Science Publishers, 1986.

Deaton, A., and J. Muellbauer. "An Almost Ideal Demand System." Amer. Econ. Rev. 70(1980):312-26.

Eales, J. S., and L. Unnevehr. "Demand for Beef and Chicken: Separability and Structural Change." Amer. J. Agr. Econ. 70(1988):521-32.

Engle, R. F. "Wald Likelihood Ratio, and Lagrange Multiplier Tests." Handbook of Econometrics, vol. 2, ed. Z. Griliches and M. D. Intriligator. New York: Elsevier Science Publishers, 1984.

Farley, J. V., and M. Hinich. “Testing for a Shifting Slope
Coefficient in a Linear Model." J. Amer. Statist. Assoc. 65(1970):1320-29.

Hendry, D. F., and G. E. Mizon. "Serial Correlation as a Convenient Simplification, Not a Nuisance: A Comment on a Study of the Demand for Money by the Bank of England." Econ. J. 88(1978):549-63.

Johnson, S. R., Z. A. Hassan, and R. D. Green. Demand System Estimation. Ames: Iowa State University Press, 1984.

Moschini, G., and K. D. Meilke. "Parameter Stability and the U.S. Demand for Beef." West. J. Agr. Econ. 9(1984):271-82.

Nyankori, J. C. O., and G. H. Miller. "Some Evidence and Implications of Structural Change in Retail Demand for Meats."' S. J. Agr. Econ. 14(1982):65-70.

Ohtani, K., and S. Katayama. "A Gradual Switching Regression Model with Autocorrelated Errors." Econ. Letters 21(1986): 169-72.

Smith, T. K. "Changing Tastes: By End of This Year, Poultry Will Surpass Beef in the U.S. Diet." Wall Street J., 17 Sep. 1987.

Thurman, W. N. "The Poultry Market: Demand Stability and Industry Structure." Amer. J. Agr. Econ. 69(1987):30-37.

Tsurumi, H. "A Bayesian and Maximum Likelihood Analysis of a Gradual Switching Regression in a Simultaneous Equation Framework." J. Econometrics 19(1982): 165-82.

Wohlgenant, M. K. "Estimating Cross Elasticities of Demand for Beef." West. J. Agr. Econ. 10(1985):32229. 